\title{
Genetic and Epigenetic Mechanisms of Endometral Reciptivity Disorder in Patients Born with Low Weight
}

\author{
Melkozerova Oxana Alexandrovna ${ }^{1}$, Bashmakova Nadezda Vasilyevna ${ }^{2}$, \\ Tretyakova Tatyana Borisovna ${ }^{3}$, Schedrina Irina Dmitrievna ${ }^{1}$ \\ ${ }^{1}$ Department Reproductive Functions Preservation, Ural Research Institute of Maternity and Child Care, Ekaterinburg, Russia \\ ${ }^{2}$ Scientific Administration, Ural Research Institute of Maternity and Child Care, Ekaterinburg, Russia \\ ${ }^{3}$ Genetics Laboratory, Ural Research Institute of Maternity and Child Care, Ekaterinburg, Russia
}

Email address:

abolmed1@mail.ru (M. O. Alexandrovna)

\section{To cite this article:}

Melkozerova Oxana Alexandrovna, Bashmakova Nadezda Vasilyevna, Tretyakova Tatyana Borisovna, Schedrina Irina Dmitrievna. Genetic and Epigenetic Mechanisms of Endometral Reciptivity Disorder in Patients Born with Low Weight. Journal of Gynecology and Obstetrics. Vol. 6, No. 4, 2018, pp. 71-79. doi: 10.11648/j.jgo.20180604.11

Received: June 5, 2018; Accepted: July 12, 2018; Published: August 7, 2018

\begin{abstract}
The aim is to study genetic and intrauterine epigenetic mechanisms of endometrial receptivity disorders in patients with reproductive failures. 96 girls of adolescents with disturbed menstrual function as anomalous uterine bleeding (AUB PP) and 210 women of reproductive age, suffering from uterine infertility or miscarriage, due to "thin" endometrium were examined. All the patients were born on the deadline. Within the main cohorts, the patients were stratified according to their birth weight. Clinical anamnestic data and molecular genetic studies of polymorphic variants of sex steroids receptor genes, endothelial function regulation genes, angiogenesis and thrombophilia were analyzed using the "real-time" allele-specific polymerase chain reaction with melting curves of the amplification products using a set of reagents and protocols of the company Test Gen LTD (Russia). The risk of reproductive failures due to impaired receptivity of the endometrium is associated with the carrier of the polymorphic allele A of the VEGF2578C gene $>$ A: for patients with infertility $(\mathrm{OR}=2.73$ $(1.36-5.45), \mathrm{p}=0.01)$ and miscarriage $\mathrm{OR}=4.61(2.19-9.71), \mathrm{p}=0.01)$ and bearing the polymorphic allele $6754 \mathrm{G}$ of the PAI1 gene $6755 \mathrm{G}>4 \mathrm{G}$ : for patients with infertility $(\mathrm{OR}=8.45(3,96-18,21), \mathrm{p}=0,001)$ and miscarriage $(\mathrm{OR}=9.98(4.61-21.74)$, $\mathrm{p}=0.001)$. The carrier of polymorphism pVull-CC of the gene ESR1 397T > C is associated with an increased risk of disruption of the development of the menstrual function, manifested by abnormal uterine bleeding of the pubertal period $(\mathrm{OR}=$ $4.58(0.97-21.68) \mathrm{p}=0.04)$, and the risk of developing in the reproductive age of miscarriage, caused by a "thin" endometrium $(\mathrm{OR}=6.79(1.94-23.75), \mathrm{p}=0.01)$. In women born with low weight, a significantly higher frequency of genotypes containing polymorphic allele 786C of the gene for endothelial NO-synthase NOS3 $786 \mathrm{~T}>\mathrm{C}$ was determined: for women with infertility $\mathrm{OR}=6.173(1.83-20.83) ; \mathrm{p}=0.001 ;$ for women with miscarriage $\mathrm{OR}=4.902(1.69-14.08) ; \mathrm{p}=0.002 ;$ for girls $\mathrm{OR}=2.56$ (1.01-6.50); $\mathrm{p}=0.04$. The genetic network containing the described variable alleles coordinates the pathological nature of the regulation of the endometrial function, which can lead to the formation of a "thin" non-receptive endometrium in response to traumatic injury.
\end{abstract}

Keywords: Endometrial Receptivity, "Thin" Endometrium, Genetic Regulation, Epigenetic Regulation, Low Birth Weight

\section{Introduction}

At present, the problems of the influence of intrauterine epigenetic factors on the realization of the receptivity of the endometrium in the reproductive age remain insufficiently studied in the world science. According to the WHO Global Survey, about 20 million children with a low birth weight
$(<2500 \mathrm{~g})$ are born every year around the world, of which about 10.2 million babies are born with a low birth weight (LBW) [1-2]. This is $27 \%$ of all live births. Recent systematic reviews confirm that the metabolic effects associated with low birth weight appear at a very young age and persist throughout life. The development of people born with low body weight, metabolic syndrome, obesity, 
hypertension, type 2 diabetes and endothelial dysfunction has been proven [3-5]. There are common epigenetic mechanisms for the formation of this pathology, predetermined by in utero programmable hypermethylation of the promoter regions of a number of genes and histone modification [6-7], which in adults can influence the functional regenerative capacity of various human tissues, including proliferation, vascular stromal remodeling, recruiting of immunocompetent cells, neoangiogenesis and regeneration in the endometrium. Similar works in the world literature are few and require further research confirming these provisions.

The aim of the study was to study some molecular genetics and intrauterine epigenetic mechanisms of endometrial receptivity disorders in patients with reproductive failures.

\section{Material and Methods of Investigation}

96 girls of adolescents with disturbed menstrual function as anomalous uterine bleeding (AMK PP) and 210 women of reproductive age, suffering from uterine infertility or miscarriage, due to "thin" endometrium were examined. All the patients were born on the deadline. Among the adolescent girls, the first main group consisted of 32 girls of pubertal age, born in a term of low birth weight (LBW: less than 10 percentages in terms of height), suffering from menarche AMK PP. The second main group consisted of 37 girls of pubertal age, born in a term with a normal birth weight NBW: more than 10 percentages in terms of height and weight, suffering from menarche abnormal uterine bleeding in the pubertal period. The control group consisted of 27 girls of pubertal age, born in a term with a normal body weight with the right rhythm of menstruation with menarche, harmonious physical and sexual development.

Among 210 women of reproductive age, 92 women with a uterine infertility were included and 90 women with miscarriage due to a "thin" endometrium. To study the role of intrauterine programming in the formation of endometrial receptivity disorders, reproductive-age patients were stratified by birth weight and divided into 4 groups: 126 women with infertility, born with LBW, 66 women with infertility, born with NBW, 35 women with miscarriage, with LBW, 55 women with miscarriage, born with NBW.

The control group consisted of 28 healthy fertile women who did not have a history of miscarriages, who had an anamnesis of urgent labor through natural birth canals without deviating from the physiological course of pregnancy and labor, resulting in the birth of healthy children.

The criteria for inclusion in the study for adolescent girls: age 12-15 years, lack of experience of sexual contacts, the presence of uterine bleeding puberty period for patients of the main study groups, gestational age at the time of birth 37 weeks or more.

The criteria for inclusion in the study for women: the reproductive age (18 - 40 years); uterine factor of infertility and miscarriage, caused by endometrial hypoplasia; thickness of the endometrium is not more than $7 \mathrm{~mm}$ per day $\mathrm{LH}+7$ (the period of the supposed "implantation window"), normocoagulation.

The criteria for exclusion from the study for adolescent girls: the presence of a blood disorder with a violation of hemostasis, other severe extragenital diseases, organic pathology of the genital organs (adenomyosis, congenital malformations, tumors and tumors of the genital organs), specific inflammatory diseases and genital tract injuries, bloody discharge from the genital tract of unknown origin at the time of treatment, taking medications that affect the blood coagulation system.

Exclusion criteria: age less than 18 and over 40 years; oncological diseases, somatic pathology, in which pregnancy is contraindicated; infertility and miscarriage, not associated with endometrial hypoplasia.

The analysis was subjected to anamnesis and clinical examination data. Anamnestic data were obtained as a result of a personal interview with patients, additional information was obtained from the exchange cards of pregnant and outpatient cards and child observation cards (form 112). Particular attention was paid to the evaluation of body weight and growth of patients at birth. In accordance with the provisions of the Helsinki Declaration of the World Medical Association the last revision, all patients and / or their legal representatives received informed consent to participate in the study and use of biological material prior to entry into the study. The examination of children was carried out with the consent of teenage girls and their parents, in the presence of parents.

The material for molecular genetic testing was DNA samples of women isolated using commercial sets of reagents "Cytolysin" TU 9398-108-01897593-10 and protocols for DNA isolation of LLC InterLabService LLC, Russia.

To estimate the amount of isolated genomic DNA, a set of KVM reagents was used to control the collection of material for the PCR method (DNA-Technology NPO, Russia). In the study, at least $1.0 \mathrm{ng}$ of genomic DNA was taken for the reaction.

The following polymorphic variants of genes were studied: genes of sex steroids receptors: ESR1 351A> G (rs9340799, xbal), ESR1 397T> C (rs2234693, Pvull), PGR 660 A $>$ G (rs1042838); genes of regulation of endothelial function: NOS3 786T $>$ C (rs2070744), NOS3 894G > T (rs1799983); genes for the regulation of angiogenesis: VEGF-A $936 \mathrm{C}>\mathrm{T}$ (rs 3025039), VEGF-A-634 G> C (rs 2010963); genes of thrombophilia: PAI-1 675 4G / 5G (rs 1799889), ITGA3 1565 T / S (rs5918), ITGA2 807 C / T (rs1126643).

DNA samples were isolated from fresh whole blood taken in an amount of $2 \mathrm{ml}$ in a disposable tube with $0.1 \mathrm{ml}$ of $6 \%$ EDTA using a kit for the isolation of whole blood cell DNA "Cytolysin" (Russia TU 9398-108-01897593-10). Allelespecific polymerase chain reaction (PCR) was then carried out in "real-time" mode; with the melting curves of the amplification products removed using a set of reagents and protocols from OOO Testgen (Russia). The detection and interpretation of the results of the research was carried out by the software of the DT-96 device manufactured by the NPO 
"DNA-Technology".

The statistical processing of the results of the research was carried out using software packages "StatSoft Statistica 6.0" (StatSoft, USA), SPSS Statistics version 22.0 (IBM Microsoft, USA). In the case of subordination of the distribution of the sign to the law of normal distribution, the data were represented as the mean value $(\mathrm{M})$ and the standard error of the mean (m). A check of statistical hypotheses about the absence of intergroup differences in quantitative characteristics in independent groups was carried out using the single-factor analysis of variance analysis (ANOVA). In the deviation of the distribution of the feature from the law of normal distribution, the data were presented as a median (Me) and lower and upper quartiles (25th and 75th percentiles, P25-P75). For the indicators characterizing the qualitative characteristics, the absolute value and the relative value in percent were indicated, the verification of the statistical hypotheses was carried out using the chi-square test $(\chi 2)$. The critical significance level of the differences (p) at which the null hypothesis of the absence of differences was rejected and the alternative hypothesis was accepted was established to be 0.025 (Kruskel-Wallis criterion) and $p$ $<0.05$ (Wilcoxon test).

The distribution of genotypes was checked for compliance with the Hardy-Weinberg equilibrium using the $\chi 2$ criterion, and also when compared with the DeFinetti parabola. Differences in the frequency of alleles and genotypes between groups are estimated by the Pearson $\chi^{2}$ criterion. To assess the association of genotypes and alleles with preeclampsia, odds ratio (OR) ratios are calculated with a $95 \%$ confidence interval $(\mathrm{CI})$.

\section{Results and Discussion}

Correct formation of a functionally complete endometrium begins at the stage of intrauterine development. In the antenatal period, the formation of the reproductive system occurs under the influence of both genetic and epigenetic factors [8-9]. The course of pregnancy and childbirth in the mother has a decisive influence on the development of reproductive health of the girl $[8,10]$. It is known that the violation of menstrual function is more often formed in girls born from mothers, whose pregnancy was taking place against the background of habitual miscarriage, preeclampsia and chronic fetoplacental insufficiency with the outcome in the fetal development delay syndrome [9-10]. The development in people born with low body weight, metabolic syndrome and obesity, arterial hypertension and endothelial is proved [3-5].

In our study, girls born with fetal growth retardation syndrome had a significantly higher body mass index bordering on the norm at the time of pubertal age and at the same time the smallest growth as compared to girls born with normal body weight (Figure 1).

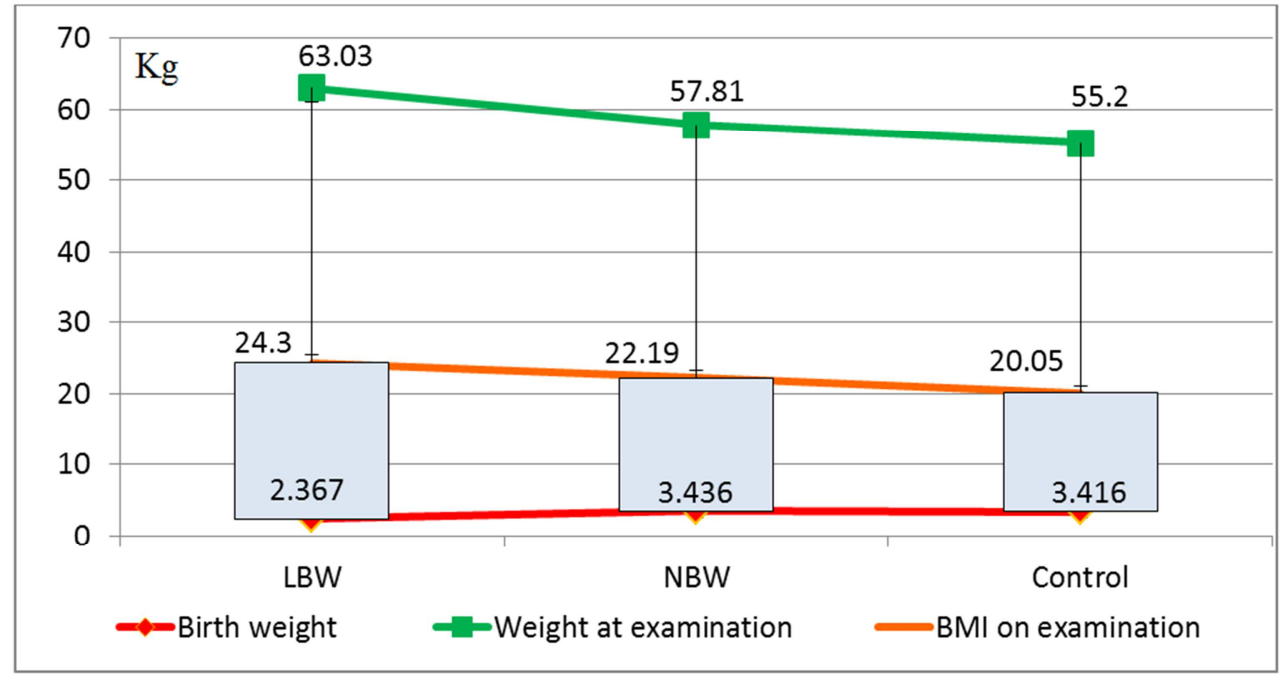

Figure 1. Age dynamics of anthropometric data of adolescent girls in the observation group $(n=96 ; M e)$.

This fact can be explained by David Backer's theory of intrauterine programming of some diseases in people born with low body weight, and especially obesity [5, 11, 12]. Mechanisms involved in metabolic programming are only beginning to be explored. According to some data, the delay in intrauterine growth of the fetus leads to a wide spread of changes in DNA methylation, thus effecting epigenetic influences on the implementation of the genomic response
[13].

It should be noted that the anthropometric features described above persist throughout life. So according to our data, in the reproductive age, women born with intrauterine growth retardation differed from their peers born with normal weight, higher body mass index values with average growth values (Figure 2). 


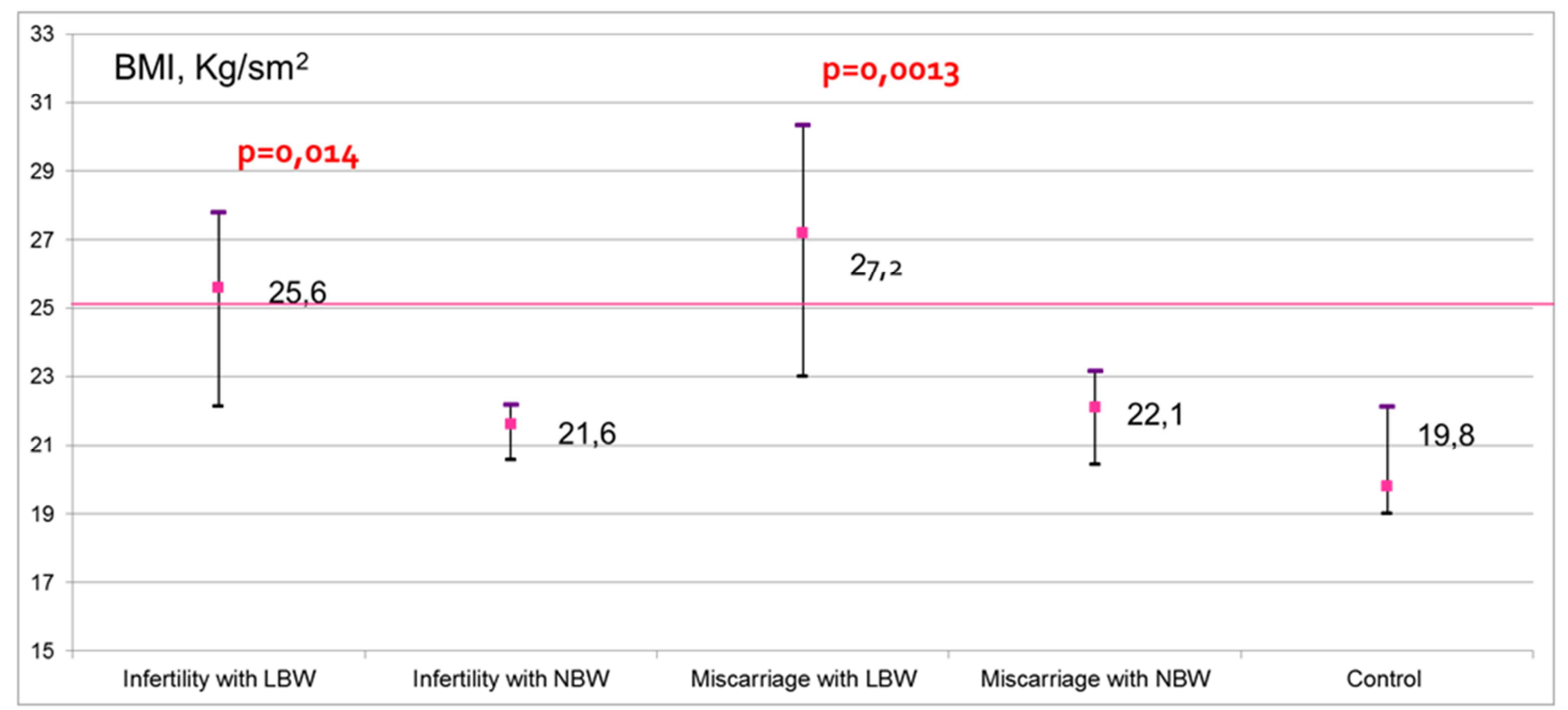

Figure 2. The body mass index of women of reproductive age in the observation groups, depending on the body weight at birth.

Every fifth patient with infertility (19.23\%) and every third patient with a habitual miscarriage (34.29\%), born with a low birth weight, had excess weight in the reproductive age.

According to our work, the heredity of patients born with low weight was most often aggravated by diabetes mellitus in $31.3 \%$ of women in the main group with LBW, in $28.3 \%$ of the girls in the main group with LBW, in control - $3.7 \%$; and arterial hypertension - in $64.9 \%$ of the girls in the main group with LBW and $56.3 \%$ in the main group with LBW, respectively, versus $20.2 \%$ in the control group. This is consistent with the higher risk of developing arterial hypertension, stroke, and diabetes mellitus in people with a low birth weight for gestational age [5-6].

It should be especially noted the higher frequency of the formation of secondary amenorrhea and Asherman's syndrome in patients born with low weight. So, according to our data, almost a quarter of patients (23.08\%), suffering from organic pathology of the uterus, accompanying the development of "thin" endometrium, were born with low weight for their gestational age. The substrate of organic damage to the uterus was Asherman's syndrome in $76.92 \%$, developmental defects of the uterus (7.69\%), submucous uterine myoma (15.39\%). In $80.76 \%$ of these patients, chronic endometritis was diagnosed.

In the pubertal period, frequent respiratory infections (46.2\%), disorders of fat metabolism $(22.4 \%)$, cardiovascular diseases $(56.25 \%)$ and gastrointestinal pathology were the most common somatic diseases in girls born with NWFP (81, $3 \%$ ). Similarly, the structure of somatic pathology also appears in women of reproductive age, born with low body weight. There were frequent respiratory viral diseases $(42.31 \%)$, diseases of the blood coagulation system $(15.38 \%)$, obesity $(19.3 \%)$ and cardiovascular diseases
(34.61\%). In our opinion, the intra-uterine programmed syndrome of endothelial dysfunction is the basis for such a high incidence of metabolic syndrome, hypertension and pathology of the hemostatic system among women born with low weight.

The role of genetic polymorphism of endothelial NOsynthase (NOS3) in the development of preeclampsia and placental insufficiency was proved [14-16]. Therefore, it is logical to assume that women born with fetal growth retardation from mothers, whose pregnancy was taking place against the background of endothelial dysfunction syndrome with the outcome of preeclampsia and feto-placental insufficiency, inherited a certain polymorphism of genes that regulate endothelial function.

Phenotypically endothelial dysfunction in them is realized in the development of metabolic syndrome, arterial hypertension, violation of the blood coagulation system, as well as in the violation of menstrual function associated with a change in the balance of tissue endothelial factors, regulators of vascular tone, angiogenesis and local hemostasis in the endometrium [17].

We conducted a study of the polymorphism of $786 \mathrm{~T}>\mathrm{C}$, $894 \mathrm{G}>\mathrm{T}$ genes in girls born with intrauterine growth retardation, having a disorder of menstrual function as an abnormal uterine bleeding, as well as in adult women born with intrauterine growth retardation and suffering from infertility and miscarriage, caused by a "thin" endometrium. Analysis of the frequency distribution of the alleles of the NOS3 genes showed an absolutely identical pattern: the frequency of the polymorphism of the NOS3 786T $>\mathrm{C}$ gene was significantly higher in both girls and women of the observation groups born with fetal growth retardation syndrome (Figures 3 and 4). 


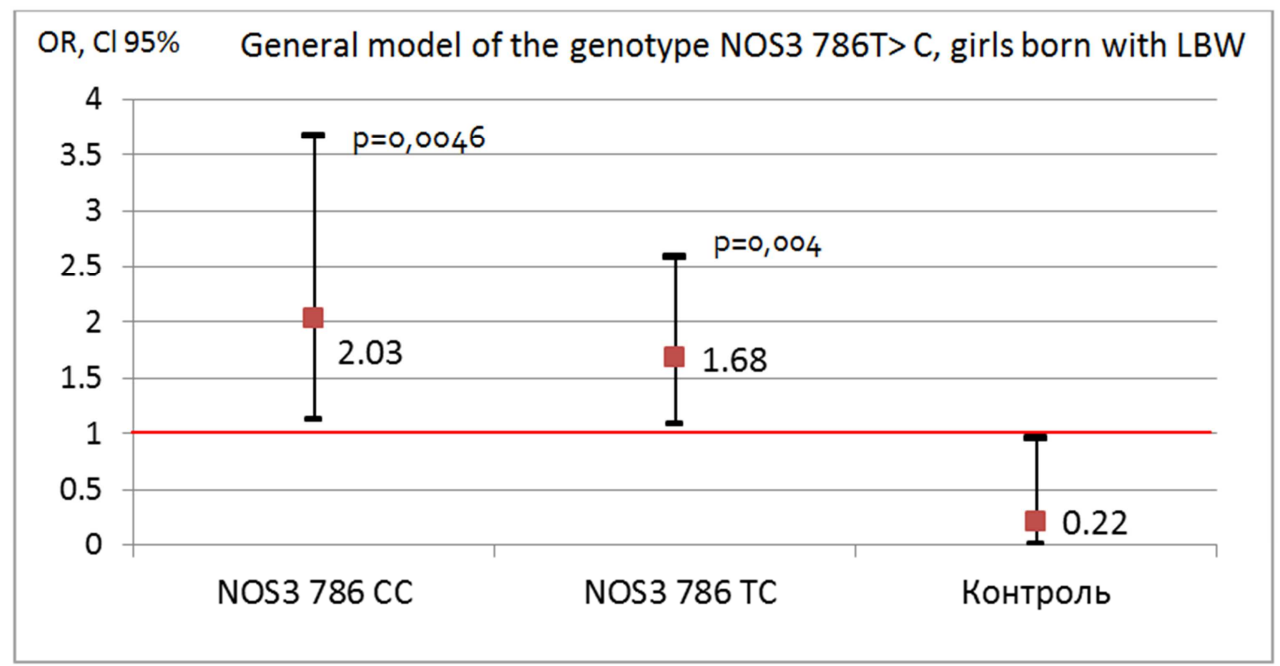

Figure 3. Frequency distribution of genotypes containing the polymorphic allele C in the NOS3 $786 T>C$ gene in adolescent girls born with LBW, OR (CL95\%).

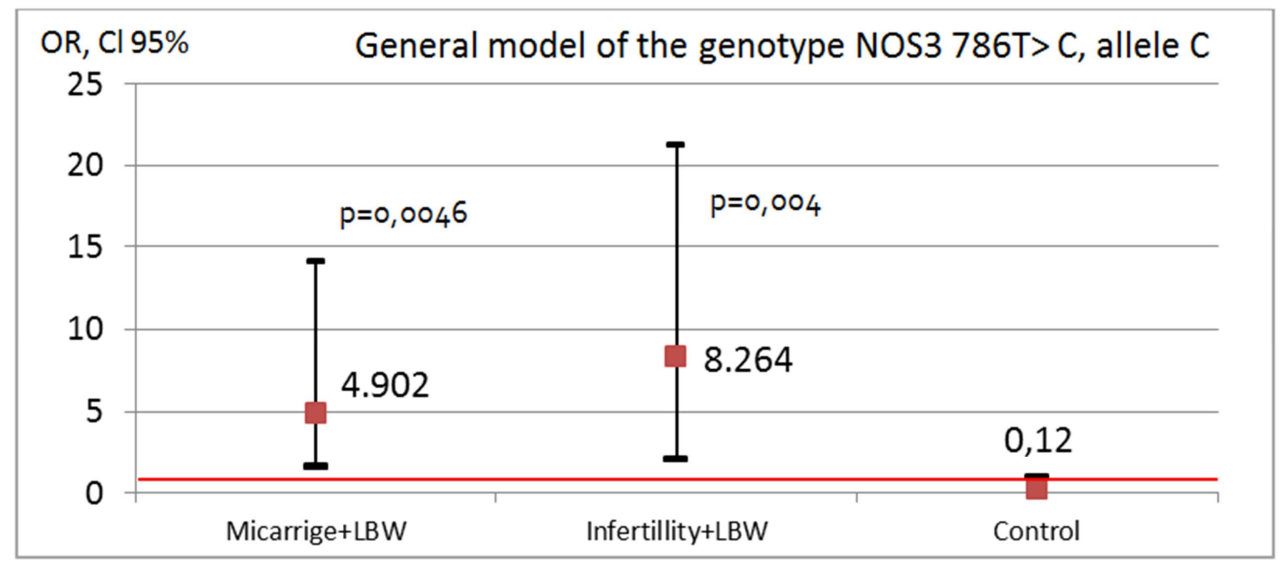

Figure 4. Distribution of carrier frequencies of genotypes containing polymorphic allele C in NOS3 786 T>C, in women of the main observation groups born with $L B W$, OR (CL95\%).

According to our data, women with low birth weight have a significantly higher incidence of genotypes containing the polymorphic allele $-786 \mathrm{C}$ of the gene for endothelial NO synthase NOS3 $786 \mathrm{~T}>\mathrm{C}$ : for women with infertility $\mathrm{OR}=$ 8.264 (1.83-20.83); $\mathrm{p}=0.001$; for women with miscarriage $\mathrm{OR}=4.902(1.69-14.08) ; \mathrm{p}=0.002$; for adolescent girls suffering from impaired menstrual function $\mathrm{OR}=2.56(1.01$ $6.50) ; p=0.04$. Thus, the carrier of the polymorphic allele $C$ in the locus 786 of the endothelial NO synthase gene observed by us in females born with low weight may be associated with a risk of developing a syndrome of endothelial dysfunction in them.

Recent work has shown that the presence of the $\mathrm{C}$ allele in the promoter of the $786 \mathrm{~T}>\mathrm{C}$ NOS3 gene leads to a decrease in the activity of endothelial NO synthase (NOS3) and reduces its expression in tissues, resulting in decreased synthesis and release of nitric oxide, which determines the endothelial syndrome dysfunction [18]. It is reported that carriers of $\mathrm{C}$ gene $786 \mathrm{~T}>\mathrm{C}$ NOS3 have lower levels of nitrites in the blood, they have a reduced response of compensatory activation of blood flow in the brachial artery to the introduction of acetylcholine and estrogens [19]. A meta-analysis from 20 studies, including 11236 patients, demonstrated the association of the polymorphic allele $\mathrm{C}$ in the $786 \mathrm{~T}>\mathrm{C}$ NOS3 gene with the presence of an increased tone of the coronary arteries, a propensity for coronarospasm and a perverted response to the administration of acetylcholine, which can serve as the basis for the development of coronary artery disease and acute coronary syndrome (OR 1.32, Cl 95\% 1.07-1.28, p = 0.001) [20].

In our study, the ESR1 Pvull-CC genotype in the estrogen receptor alpha gene was more often determined in girls with uterine puberty bleeding and in adult women suffering from miscarriage with a "fine" endometrium. 


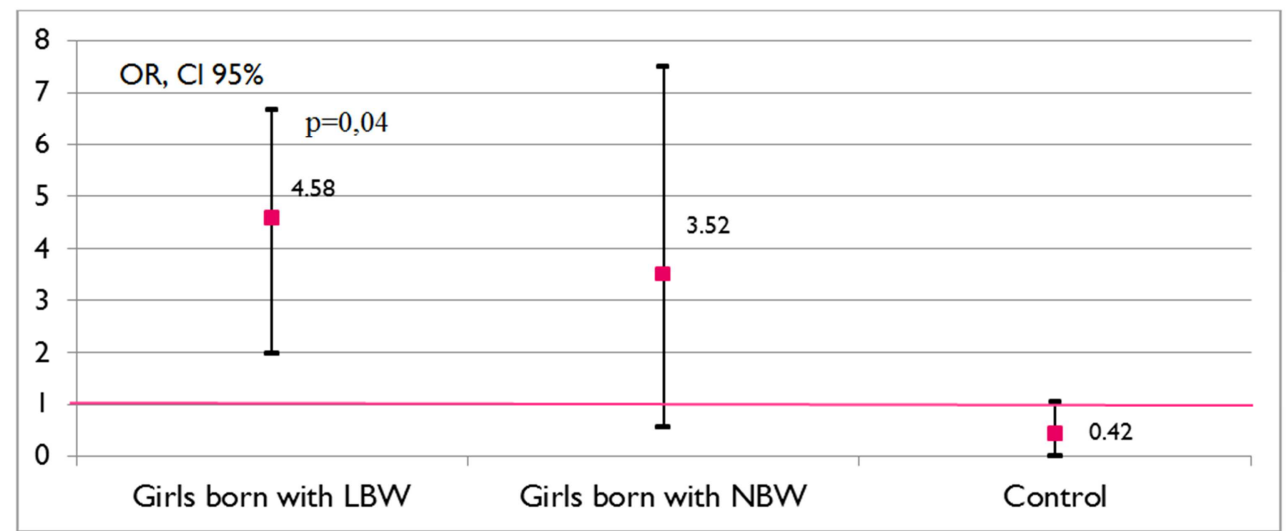

Figure 5. Frequency distribution of the genotype of the gene ESR1 397 T>C (polymorphism P-vull) in the observation groups of adolescent girls, OR (CL95\%).

In studies on the effect of pVull ESR1 polymorphism on endothelial dysfunction in cardiovascular disease, it is emphasized that the ESR1 genotype of Pvull-CC carries an increased risk of endothelial dysfunction and is clinically more likely to increase systolic blood pressure, intima thickness and IHD in women [21-22]. In the works of other authors it is emphasized that the genotype ESR1 Pvull-CC significantly reduces the NO-dependent increase in blood flow velocity and bioavailability of $\mathrm{NO}$ [23].

A number of researchers believe that the syndrome of endothelial dysfunction causes a decrease in blood flow in the stroma of the endometrium and the formation of tissue hypoxia $[17,22]$. In our study, a significant reduction in blood flow in the subendometral area was shown, accompanied by an increase in indices of resistance in the spiral arteries of the uterus in girls with AMC PP, born with low weight, as well as in women with "thin" endometrium, suffering from infertility or miscarriage. Tissue hypoxia in this case triggers the development of abnormal angiogenesis, due to the formation of cells expressing vascular endothelial growth factor (VEGF) intensively. Locwood C. J. et al., 2011 [17] have shown that tissue hypoxia associated with inhibition of endometrial blood flow activity and hyperproduction of active oxygen species in endothelial dysfunction syndrome increases the synthesis of angiogenic growth factors such as VEGF-A in HESC and angiopoietin-2 (Ang -2) in the endothelial cells of the endometrium, while the synthesis of angiopoietin-1 in HESC cells decreases [17]. As a result, the fragility of the vascular wall increases. In young adolescent girls, this can lead to the development of abnormal uterine bleeding. In the reproductive age, dysregulation of angiogenesis and lymphangiogenesis in the endometrium can be an important pathogenetic mechanism for disturbing the regeneration of the endometrium in response to trauma. Initially, the strategy of formation of proangiogenic status is, apparently, one of the compensatory mechanisms for maintaining optimal tissue perfusion in the endometrium when the conditions of its existence are violated. However, in the future, any adverse effect on the endometrium during the reproductive age of this category of women (carriers of certain polymorphic alleles of the NOS, ESR1, VEGFA) may have a potentially dangerous high risk of developing a "thin" refractory endometrium against its regenerative-plastic deficiency.

According to our data, the carriage of polymorphism of the pVull-CC polymorphism of the ESR1 397T> C gene is associated not only with an increased risk of disruption of the menstrual function, which is manifested by abnormal uterine bleeding of the pubertal period $(\mathrm{OR}=4.58(0.97-21.68) \mathrm{p}=$ $0,04)$, but also the risk of developing a miscarriage in the reproductive age due to the "thin" endometrium $(\mathrm{OR}=6.79$ (1.94-23.75), $\mathrm{p}=0.01$ ).

On the other hand, an anomaly of angiogenesis in the endometrium will inevitably lead to a change in the rhythm of expression of steroid receptors and the production of growth factors in the endometrium due to a change in the transcriptional profile of genes in response to the epigenetic influence of the tissue hypoxia factor [24].

In confirmation of the role of abnormal angiogenesis in the formation of "thin" refractory endometrium in patients with reproductive failures, it should be noted that the carrier frequencies of the $-2578 \mathrm{~A}$ allele in the locus rs699947 of the VEGF $2578 \mathrm{C}>\mathrm{A}$ gene were significantly increased in the cohort of women with infertility $(\mathrm{OR}=2,73(1.36-5.45), \mathrm{p}=$ $0.01)$, and among patients with habitual miscarriage (OR $=$ $4.61(2.19-9.71), \mathrm{p}=0.01)$ (figure 6). 


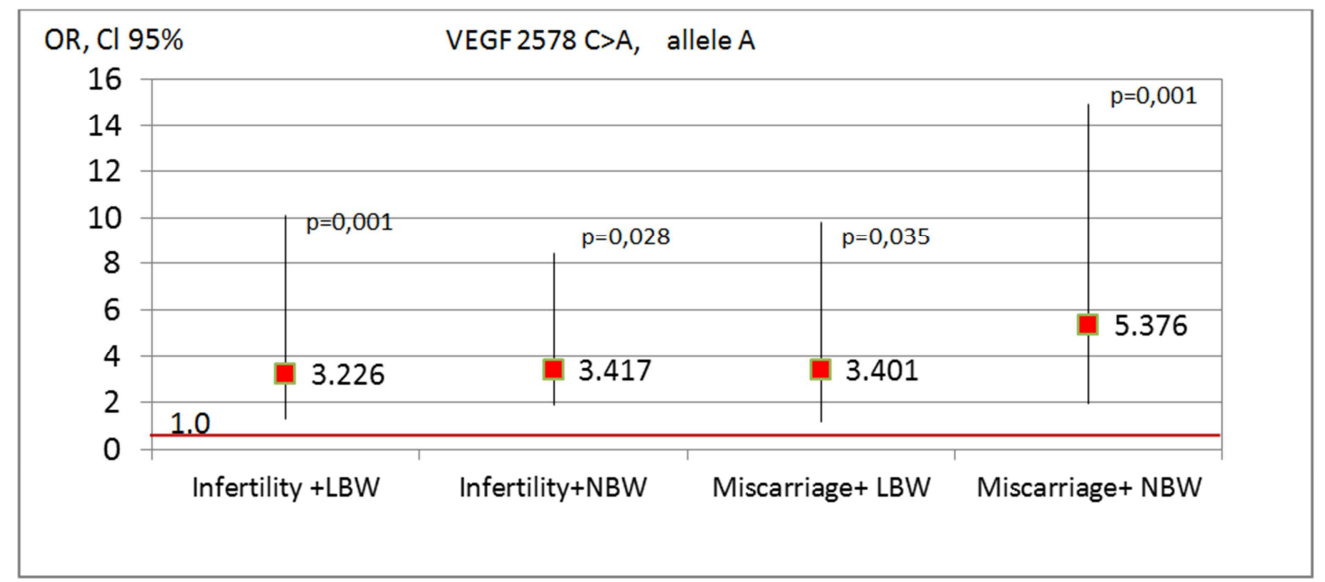

Figure 6. Distribution of carrier frequencies of the -2578A allele in the locus rs699947 of the gene VEGF 2578 C>A in the observation groups, OR (CL95\%).

Vascular endothelial growth factor (VEGF) induces the formation of new vessels by stimulating, dividing and migrating endothelial cells of nearby vessels [25]. VEGF specifically binds to two transmembrane tyrosine kinase receptors (VEGFR) on endothelial cells for transduction of the intracellular signal required for angiogenesis [25]. According to several authors, carriage of the genotype $\mathrm{CC} /$ $\mathrm{CA}$ of the gene VEGF $2578 \mathrm{C}>\mathrm{A}$ is associated with an increase in the synthesis of VEGF-A in plasma and the risk of metastasizing a number of epithelial cancers; In contrast, the variant $-2578 \mathrm{~A}$ allele is associated with a decrease in the transcription of the AP-protease and the synthesis of VEGF$A$ in tissues [26-27]. A decrease in VEGF-A production may account for the low activity of angiogenesis in tissues, including endometrium, in carriers of the genotype AA / AC of the VEGF $2578 \mathrm{C}>\mathrm{A}$ gene [28].

Another essential link in the genetic network associated with the regulation of the endothelial function is the genes coding for the synthesis of fibrinolysis factors by vascular endothelium (PAI-1 5G / 4G). In particular, the SERPINE1 gene, belonging to the serpin family, encodes the endothelial inhibitor of plasminogen activator-1 (IAP-1). According to the literature, in homozygous for $4 \mathrm{G}$ allele (genotype $4 \mathrm{G} /$ $4 \mathrm{G})$ of the SERPINE1 gene, an increase in the concentration of the IAP-1 protein in blood plasma leads to an increased risk of miscarriage and formation of retroplacental hematomas $[22,29]$. On the other hand, the presence of the $5 \mathrm{G}$ allele is associated with less inhibition of the plasminogen activator and, as a consequence, with increased activation of uterine metalloproteinases, which play an important role in the processes of stromal secretory remodeling and invasion of the cytotrophoblast [30]. The carrier of the polymorphic $4 \mathrm{G}$ allele can contribute to inferior stromal remodeling of the endometrium (due to low MMP activity), insufficient invasion of the cytotrophoblast into the spiral arteries, and the formation of microangiothrombosis associated with inhibition of fibrinolysis. These mechanisms can underlie the pathogenesis of an undeveloped pregnancy and early spontaneous abortions.

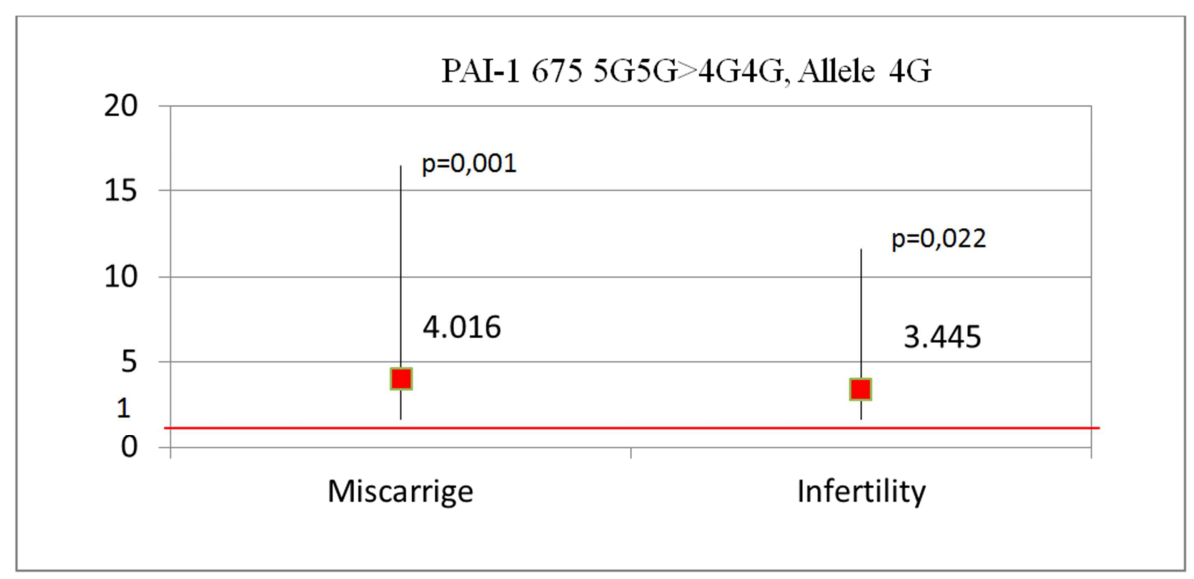

Figure 7. Distribution of carrier frequencies of the allele - $4 G$ in the locus of the PAI-1 gene $6755 G 5 G>4 G 4 G$ in the observation groups, OR (CL95\%).

According to our study (Figure 7), the genotypes of women suffering from infertility and miscarriage due to the "thin" endometrium were significantly more likely to contain the polymorphic allele $-6754 \mathrm{G}$ of the SERPINE1 gene compared to fertile healthy patients: for patients with infertility $(\mathrm{OR}=8,45(3.96-18.21), \mathrm{p}=0.001)$ and miscarriage $(\mathrm{OR}=9.98(4.61-21.74), \mathrm{p}=0.001)$. 


\section{Conclusion}

Summarizing the results of molecular genetic studies, it is worthwhile to note once again the multifactor nature of the diseases leading to the formation of a "thin" refractory endometrium. And this is quite understandable from the point of molecular genetics. A gene network that controls a particular phenotypic sign of an organism usually includes from several dozen to hundreds of genes. For many years, genetic polymorphism studies have focused on finding a "universal marker of the disease." However, attempts to discriminate groups by one marker are usually ineffective.

World scientific research is currently focused on the creation and clinical application of the genetic network of the transcriptome of the endometrial receptivity array (ERA) genes. Intergenic associations of genes of sex steroid receptions, angiogenesis, endothelial function, thrombophilia and a number of other groups of genes form a network within which molecular genetic mechanisms are regulated for the growth, differentiation and morphogenesis of endometrial cells. In our study, it was shown that the intrauterine effect of hypoxia, as an epigenetic factor, activates the expression of endothelial NOS3 genes. This leads in girls and women born with intrauterine growth retardation syndrome to the formation of in uteroprogrammed endothelial dysfunction, which is realized by the imbalance of regulation of local angiogenesis, the synthesis of tissue growth factors, vasoconstriction and fibrinolysis in the endometrium. In carriers of polymorphism Pvull of the estrogen receptor gene, the situation is aggravated by a decrease in the activity of ESR1 estrogen receptor proteins, which further reduces the angiogenic and proliferative potential of endometrial tissue. The genetic network containing the described variative alleles coordinates the pathological nature of the regulation of endometrial function, which leads to the development of the disease in response to the action of the trigger factor, which is most often the endometrial injury. Since, according to evolutionary biology, it is the accumulation of mutations in various parts of the gene network that forms the disease.

\section{References}

[1] Black R. E. Global Prevalence of Small for Gestational Age. Births. Nestle Nutr. Inst. Workshop. Ser. 2015; 81: 1-7. http://doi:10.1159/000365790

[2] Lee A. C., Katz J., Blencowe H.. National and regional estimates of the term and preterm of babies born in the lowincome and middle-income countries in 2010. Lancet Glob Health. 2013; 1 (2): 26-36. https://doi.org/10.1016/S2214109X(13)70006-8

[3] Barker D. J. The origins of the developmental origins theory. J. Intern. Med. 2007; 261 (5): 412-417.

[4] Chernausek S. D. Update: Consequences of Abnormal Fetal Growth. J. Clin. Endocrinol. Metab. 2012; 97: 689-695. https://doi.org/10.1210/jc.2011-2741
[5] Voerman E, Jaddoe VW, Franco OH, Steegers EA, Gaillard R. Critical periods and growth patterns from fetal life onwards associated with childhood insulin levels. Diabetologia. 2017; 60(1): 81-88. https://doi.org/10.1007/s00125-016-4135-9

[6] Christian L. R., Sheela S. Mechanisms of neuroendocrine and epigenetic regulation of body weight and onset of puberty. Rev. Endocr. Metab. Disord. 2012; 13: 129-140.

[7] Kawai T., Yamada T., Abe K., Okamura K., Kamura Hi., Akaishi R. Increased epigenetic alterations at the promoters of transcriptional regulators following inadequate maternal gestational weight gain. Sci Rep. 2015; 5: 142-224. https://doi.org/10.1038/srep03843

[8] Baranov AA, Kuchma VR, Namazova L. S. Health and development of adolescents in Russia. M.: NTSZD RAMS; 2010. 102 p.

[9] Talib HJ. Adolescent Gynecology. Springer; 2018. 23 p.

[10] Dankova IV, Bashmakova NV, Chistyakova G. N. Peculiarities of puberty flow in adolescent girls born with manifestations of intrauterine growth retardation. Reproductive health of children and adolescents. 2013; 1: 44-52.

[11] Barker D. J. Intrauterine programming of adult disease. Mol. Med. Today. 1995; 1 (9): 418-423.

[12] Nasr H. B., Dimassi S., M'hadhbi R. Functional G894T (rs1799983) polymorphism and intron-4 VNTR variant of nitric oxide synthase (NOS3) gene are susceptibility biomarkers of obesity among Tunisians. Obes. Res. Clin. Pract. 2015; 5 (4): 1871-1903. https://doi.org/10.1016/j.orcp.2015.04.008

[13] Chan Y, Salem RM, Hsu YH, McMahon G, Pers TH, Vedantam S, Esko T, Guo MH, Lim ET et al. Genome-wide Analysis of Body Proportion Classifies Height-Associated Variants by Mechanism of Action and Implicates Genes Important for Skeletal Development. Am J Hum Genet. 2015 May 7; 96(5):695-708.

https://doi.org/10.1016/j.ajhg.2015.02.018

[14] Ali S. M., Khalil R. A. Genetic, Immune, and Vasoactive Factors in the Vascular Dysfunction Associated with Hypertension in Pregnancy. Expert. Opin. Ther. Targets. 2015; 19 (11): 1495-1515.

https://doi.org/10.1517/14728222.2015.1067684

[15] Haram K. Genetic Aspects of Preeclampsia and the HELLP Syndrome. J. Pregnancy. 2014; 9: 107-151.

[16] Leonardo D. P., Albuquerque D. M., Lanaro C. Association of Nitric Oxide Synthase and Matrix Metalloprotease Single Nucleotide Polymorphisms with Preeclampsia and Its Complications. PLoS One. 2015; 10 (8): 66 - 93. https://doi.org/10.1371/journal.pone.0136693

[17] Lockwood C. J., Nemerson Y., Guller S. Decidualized Human Endometrial Stromal Cells Mediate Hemostasis, Angiogenesis, and Abnormal Uterine Bleeding. Reprod Sci. Feb. 2009; 16 (2): 62-170. https://doi.org/10.1177/1933719108325758

[18] Asif A. R., Oellerich M., Armstrong V. W. Polymorphism of the nos-3 Gene and the Endothelial Cell Response to Fluid Shear Stress - A Proteome Analysis. Journal of Proteome Research. 2009; 8 (6): 3161-3168. https://doi.org/10.1021/pr800998k 
[19] Monti L. D., Galluccio E., Fontana B. Pharmacogenetic influence of NOS3 gene variant on endothelial and glucose metabolism responses to L-arginine supplementation: Post hoc analysis of the L-arginine trial. Metabolism. 2015; 64 (11): 1582-1591.

[20] Sung J. H., Lee B. E., Kim J. O. Association between NOS3 polymorphisms and risk of coronary artery disease in a Korean population: a meta-analysis. Genet. Mol. Res. 2015; 9 (4): 16508-16520. https://doi.org/10.4238/2015

[21] Ozsoy A. Z., Karakus N. H., Yigit S.G. The Evaluation of IL6 and ESR1 Gene Polymorphisms in Primary Dysmenorrhea. Immunol Invest. 2016; 45: 75-86.

[22] Shen C., Chen J., Fan S. Association between the polymorphism of estrogen receptor $\alpha$ and coronary artery disease in a Chinese population. European Journal of Internal Medicine. 2012; 23: 175-178. https://doi.org/10.7150/ijms.5234

[23] Clapauch R., Mourão A. F., Mecenas A. S. Endothelial function and insulin resistance in early postmenopausal women with cardiovascular risk factors: importance of ESR1 and NOS3 polymorphisms. PLoS One. 2014; 9 (7): 34-44. https://doi.org/10.1371/journal.pone.0103444

[24] Gombolevskaya NA, Burmenskaya OV, Demura TA, Marchenko LA Evaluation of mRNA expression of cytokine genes in endometrium in chronic endometrium. Obstetrics and gynecology. 2013; 11: 35-40.

[25] Joris V, Gomez EL, Menchi L, Lobysheva I, Di Mauro V,
Esfahani H, Condorelli G, Balligand JL, Catalucci D, Dessy C. MicroRNA-199a-3p and MicroRNA-199a-5p Take Part to a Redundant Network of Regulation of the NOS (NO Synthase)/NO Pathway in the Endothelium. Arterioscler Thromb Vasc Biol. 2018; ATVBAHA.118.311145. https://doi.org/10.1161/ATVBAHA.118.311145

[26] Hou Q, Li MY, Huang WT, Wei FF, Peng JP, Lou MW, Qiu JG. Association between three VEGF polymorphisms and renal cell carcinoma susceptibility: a meta-analysis. Oncotarget. 2017; Jul 25; 8(30):50061-50070. https://doi.org/10.18632/oncotarget.17833

[27] Prakash S, Agrawal S., Kumar S. Impact of Vascular Endothelial Growth Factor Single Nucleotide Polymorphism Association on Acute Renal Allograft Rejection. Nephron. 2015; 129: 91-96. https://doi.org/10.1159/000368700

[28] Liu F., Luo L., Wei Y. Association of VEGFA polymorphisms with susceptibility and clinical outcome of hepatocellular carcinoma in a Chinese Han population. Oncotarget. 2017; 8 (10): 16488-16497. https://doi.org/10.18632/oncotarget.14870

[29] Ye Y, Vattai A, Zhang X, Zhu J, Thaler CJ, Mahner S, Jeschke U, von Schönfeldt V. Role of Plasminogen Activator Inhibitor Type 1 in Pathologies of Female Reproductive Diseases. Int J Mol Sci. 2017; Jul 29; 18(8). https://doi.org/10.3390/ijms18081651

[30] Li Z. L., Ueki K., Kumagai K. Regulation of bcl-2 transcription by estrogen receptor-alpha and C-Jun in human endometrium. Med. Mol. Morphol. 2014; 47 (1): 43-53. 